\title{
Mathematical Model for Predicting Thrust Force in Drilling of GFRP Composites by Multifaceted Drill
}

\author{
T. V. Rajamurugan ${ }^{1 *}$, K. Shanmugam ${ }^{2}$ and K. Palanikumar ${ }^{3}$ \\ 'Department of Manufacturing Engineering, Annamalai University, Chidambaram-608002, India; \\ vijayaveiynil@gmail.com \\ ${ }^{2}$ Department of Manufacturing Engineering, Annamalai University, Chidambaram-608002, India; \\ Drshanmugam67@gmail.com \\ 3Department of Mechanical Engineering, Sri Sai Ram Institute of Technology, \\ Chennai-600 044, India; Palanikumar_k@yahoo.com
}

\begin{abstract}
In this work an attempt has been made to develop empirical relationships to model thrust force in drilling of GFRP composites by Multifaceted drill bit. The empirical relationships were developed by response surface methodology incorporating above drilling parameters. The developed model can be effectively used to predict the thrust force in drilling of GFRP composites within the factors and their limits are studied.
\end{abstract}

Keywords: Drilling, GFR-polyester Composites, Modelling, Thrust Force, Optimisation.

\section{Introduction}

In recent years, Glass Fiber Reinforced Plastic composites (GFRP) have been extensively used in variety of engineering applications varying from aerospace to automobile industries. GFRP possess high strength and stiffness, ease of molding complex shapes, high corrosion resistance which make the material superior to metals for many applications. GFRP composite components are commonly fabricated by filament winding, hand lay-up, resin transfer moulding process. After fabrication, they require further machining for structural assemblies.

In drilling of GFRP composites, thrust force is the important criteria and the most effective way of achieving quality holes while drilling fiber reinforced plastics is by reducing the thrust. The effect of thrust force on drilling of GFRP composites is studied by many researchers. Davim et al. [1] carried out a study on milling of Glass fiber reinforced plastic composites manufactured by hand lay-up process. They used two types of GFRP composites to evaluate the cutting parameters such as cutting velocity and tool feed rate. Murphy et al. [2] studied the Thrust forces with respect to the drill bit and the work piece being drilled. They found out that the maximum thrust force was observed during a test run when the tool reaches the bottom of the laminate. Engin et al. [3] studied the orthogonal cutting mechanisms of Medium density fibre by developing the models of mechanics of orthogonal cutting. When GFRP composites are drilled, one should concentrate on the machining and friction force acting on it. Abrao et al. [4] investigated the effect of cutting tool geometry and material on thrust force and delamination produced while drilling GFRP composites. The major problem encountered during drilling of GFRP composites is delamination, which is occurred due to the thrust force developed during machining. Latha and Senthilkumar [5] studied delamination in drilling of GFR composites. They used 3 different types of K10 carbide tools to conduct experiments. Khashaba

*Corresponding author:

T. V. Rajamurugan (vijayaveiynil@gmail.com) 
Table 1. Properties of fiber and resin

\begin{tabular}{|c|c|c|c|c|c|}
\hline Fiber/resin & $\begin{array}{l}\text { Tensile modulus } \\
\text { (E) }(\mathrm{GPa})\end{array}$ & $\begin{array}{l}\text { Tensile strength } \\
(\sigma)(\mathrm{MPa})\end{array}$ & Density $(\rho)\left(\mathrm{g} / \mathrm{cm}^{3}\right)$ & $\begin{array}{l}\text { Shear } \\
\text { modulus }\end{array}$ & $\begin{array}{l}\text { Ultimate } \\
\text { elongation (\%) }\end{array}$ \\
\hline E-Glass & 69 & 2400 & 2.6 & 27 & - \\
\hline Polyester & 3000 & 50 & 1.10 & - & $2 \%$ \\
\hline
\end{tabular}

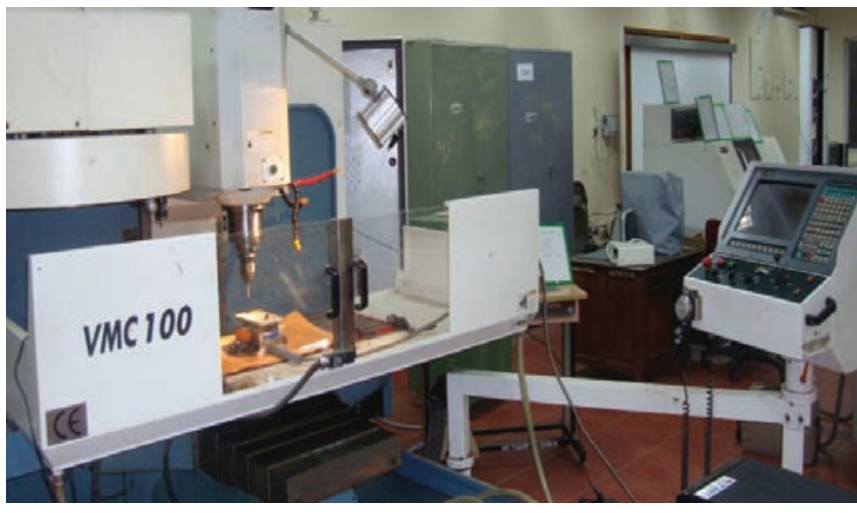

Figure 1. Close-up view of vertical machining centre (VMC100).

et al. [6] have studied the influence of material variables on thrust force, torque and delamination while drilling of GFRP composites. They have carried out the experiment with cross winding / polyester, continuous winding / polyester, woven polyester and woven /epoxy. They concluded that woven /epoxy combination posses better performance over others. Claudin et al. [7] conducted drilling experiments to determine suitable cutting tool for machining a low carbon steel using using different drill bits such as solid carbide drills, solid carbide modular drills, and indexable drills. They modeled axial force and cutting torque as a function of diameter, rake angle, cutting velocity, and feed rate and they found out the methodology to determine the drill geometry effect.

From the above literature, it has been known that the thrust force is an important concern and it has to be minimized. To get minimum thrust force, it is necessary to employ optimization techniques to find optimal cutting parameters and theoretical models to do predictions. Response Surface Methodology (RSM) is finding enormous applications in solving variety of complex engineering and scientific problems. Response Surface Methodology (RSM) is a collection of statistical and mathematical techniques useful for developing, improving, and optimizing processes. The most extensive applications of RSM are in the particular situations where several input variables potentially influence some performance measure or quality characteristic of the process [8]. Stone and Krishnamurthy [9] utilized a neural network thrust force controller to minimize delamination during drilling of graphite-epoxy laminates. Researchers successfully modeled and optimized by using a sequence of designed experiments to obtain an optimal response by knowing less about the process by using RSM [10-12]. Latha and Senthilkumar [13] have successfully applied fuzzy logic for the prediction of thrust force in drilling of GFRP composites. They used Pareto analysis of variance (Pareto-ANOVA) and analysis of variance (ANOVA) for analysis of machining parameters in drilling of GFRP composites. In the present study, effect of cutting parameters on thrust force on the drilling of GFRP composites by Multifaceted tool is evaluated and second order model is developed for predicting the thrust force. The predicted and measured values indicate that the developed model can be effectively used to predict the thrust force in the drilling of GFRP composites.

\section{Materials and Method}

The GFR-Polyester specimen used for this investigation is prepared by using hand lay-up technique. Unsaturated polyester resin matrix reinforced with $60 \%$ weight $\mathrm{E}$ - glass fiber is used for preparation and the thickness of the material is approximately $10 \mathrm{~mm}$. The density of the polymer used is $1.10 \mathrm{~g} / \mathrm{cm}^{3}$. The resin used for the fabrication of composite material is polyester and the hardner used is methyl ethyl ketone peroxide and accelerator is Kerox C-20. The specimen is having length $180 \mathrm{~mm}$, breadth $90 \mathrm{~mm}$, and height $12 \mathrm{~mm}$. The properties of the fiber and resin are presented in Table 1.

The experiments were conducted in computer numeric control (CNC) vertical machining centre (VMC100). The machining center has a maximum spindle speed of 5000 rpm with a table size of $1270 \times 254 \mathrm{~mm}$ and is presented in Figure 1. Multifaceted drill bits supplied from Woodtech USA were used for experimentation and are presented in Figure 2. Kistler piezo-electric dynamometer is used for capturing the thrust force obtained in drilling of GFRP composites, which is presented in Figure 3. 


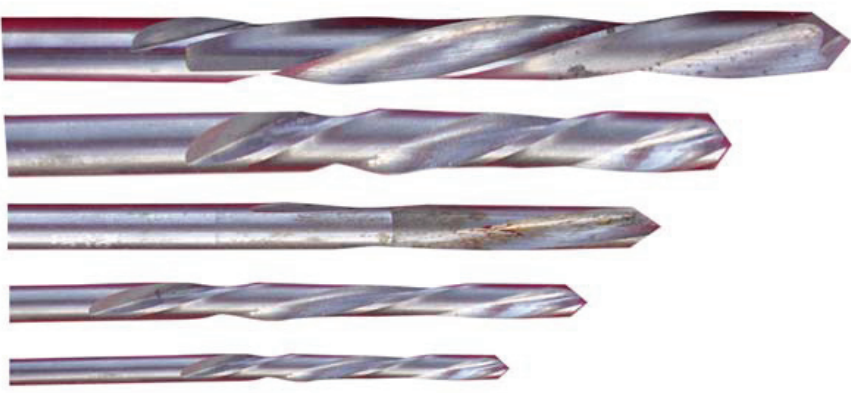

Figure 2. Multifaceted drills used for the experimentation.

Table 2. Specification of the dynamometer used for the experiment

\begin{tabular}{ll}
\hline Type & Calibrated 9257B \\
\hline Weight & $7.3 \mathrm{~kg}$ \\
Length ${ }^{*}$ Width*Height & $170 \mathrm{~mm}^{*} 100 \mathrm{~mm}^{*} 60 \mathrm{~mm}$ \\
Type of sensor & Piezoelectric \\
Number of channels & 8 \\
Multichannel amplifier-type & $5019 / 5017$ \\
Operating temperature range, ${ }^{\circ} \mathrm{C}$ & $0-70$ \\
\hline
\end{tabular}

The thrust force obtained can be measured using Multi channel amplifier type Dynamometer, whose specification is presented in Table 2 and the figure of the dynamometer is presented in Figure 3.

\subsection{Response Surface Methodology}

RSM is a collection of mathematical and statistical techniques, which are useful for predicting the models and analyzing the problems in which more than one responses are influenced by several factors. The mathematical model of the response to independent controllable factors can be predicted, by using the multiple regression analysis with minimum number of experiments planned through design of experiments [14]. In our study, the second order polynomial models have been developed to predict the Thrust force, which is influenced by feed rate (f) and cutting speed $(v)$, Drill diameter (d) and Fibre orientation angle $(\theta)$. The values of the regression coefficients of linear, quadratic and interaction terms of the mathematical models are determined by the following formula:

$$
B=\left(X^{\mathrm{t}} X\right)^{-1} X^{\mathrm{t}} Y
$$

where, $B$ is the matrix of parameter estimates, $X$ is the calculation matrix includes linear, quadratic and interaction terms, $\mathrm{X}^{\mathrm{t}}$ is the transpose of $\mathrm{X}$ and $\mathrm{Y}$ is the matrix of response.

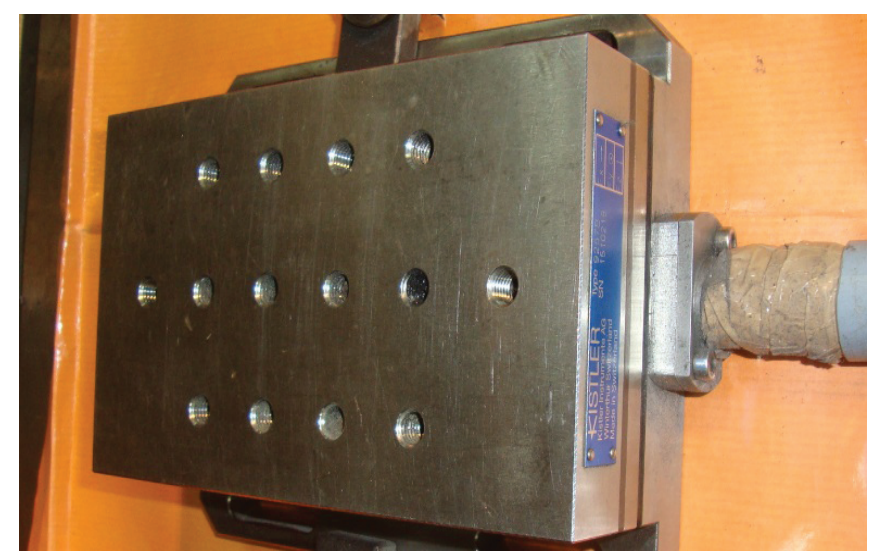

Figure 3. Close-up view of Dynamometer.

Statistical design of experiments is used for experimentation. Due to the wider ranges of parameters selected, it has been decided to use five levels, central composite, rotatable design. Central composite rotatable design of second order was found to be the most efficient tool in response surface methodology to establish the mathematical relation of the response surface using the least possible number of experiments without losing its accuracy [15]. From the literature [2-5] and the previous work conducted in this field by authors $[16,17]$, the independently controllable predominant drilling parameters which affect the Thrust force during the drilling of GFRP composite work piece have been identified. They are spindle speed $(\mathrm{N})$, feed rate (f), Drill diameter $(\mathrm{d})$ and fiber orientation angle $(\theta)$. Table 3 presents the ranges of factors considered and Table 4 shows the 30 sets of coded conditions used to form the design matrix, the parameters used, real values and output response.

The first 16 experimental conditions are derived from half factorial experimental design matrix $\left(2^{4}=16\right)$. All the variables at the intermediate (0) level constitute the center points while the combinations of each process variable at either its lowest $(-2)$ or its highest $(+2)$ with the other 8 variables of the intermediate levels constitute the star points. Thus, the 30experimental conditions allowed the estimation of the linear, quadratic and twoway interactive effects of the variables on the thrust force in drilling of GFRP composites.. For the convenience of recording and processing of the experimental data, upper and lower levels of the factors are coded as +2 and -2 , respectively [18]. 
Table 3. Control factors and level used for experimentation

\begin{tabular}{|c|c|c|c|c|c|c|c|c|}
\hline $\begin{array}{l}\text { Cutting } \\
\text { Parameters }\end{array}$ & Symbol & Unit & Range & Level 1 & Level 2 & Level 3 & Level 4 & Level 5 \\
\hline $\begin{array}{l}\text { Spindle } \\
\text { Speed }\end{array}$ & $N$ & $\mathrm{rev} / \mathrm{min}$ & $500-2000$ & 500 & 875 & 1250 & 1625 & 2000 \\
\hline Feed rate & $f$ & $\mathrm{~mm} / \mathrm{min}$ & $50-300$ & 50 & 112.5 & 175 & 237.5 & 300 \\
\hline $\begin{array}{l}\text { Drill } \\
\text { Diameter }\end{array}$ & $d$ & $\mathrm{~mm}$ & $4-12$ & 4 & 6 & 8 & 10 & 12 \\
\hline $\begin{array}{l}\text { Fiber orientation } \\
\text { angle }\end{array}$ & $\theta$ & degrees & $0-90$ & 0 & 22.5 & 45 & 67.5 & 90 \\
\hline
\end{tabular}

Table 4. The parameters used, their coded values, real values and output response

\begin{tabular}{|c|c|c|c|c|c|c|c|c|c|}
\hline \multirow[b]{3}{*}{ Exp. No } & \multicolumn{8}{|c|}{ Input parameters } & \multirow{3}{*}{$\begin{array}{l}\text { Output } \\
\text { Response } \\
\text { Thrust force } \\
\end{array}$} \\
\hline & \multicolumn{4}{|c|}{ Coded Value } & \multicolumn{4}{|c|}{ Real Value } & \\
\hline & $\begin{array}{l}\text { Spindle Speed } \\
(\mathrm{rpm})\end{array}$ & $\begin{array}{l}\text { Tool Feed } \\
\text { rate } \\
(\mathrm{mm} / \mathrm{min})\end{array}$ & $\begin{array}{l}\text { Drill } \\
\text { diameter } \\
(\mathrm{mm})\end{array}$ & $\begin{array}{l}\text { Fiber } \\
\text { orientation } \\
\text { angle, degrees }\end{array}$ & $\begin{array}{l}\text { Spindle Speed } \\
(\mathrm{rpm})\end{array}$ & $\begin{array}{l}\text { Tool Feed } \\
\text { rate }(\mathrm{mm} / \\
\text { min) }\end{array}$ & $\begin{array}{l}\text { Drill } \\
\text { diameter } \\
(\mathrm{mm})\end{array}$ & $\begin{array}{l}\text { Fiber } \\
\text { orientation } \\
\text { angle, degrees }\end{array}$ & \\
\hline 1 & -1 & -1 & -1 & -1 & 875 & 112.5 & 6 & 22.5 & 119.61 \\
\hline 2 & 1 & -1 & -1 & -1 & 1625 & 112.5 & 6 & 22.5 & 102.45 \\
\hline 3 & -1 & 1 & -1 & -1 & 875 & 237.5 & 6 & 22.5 & 175.78 \\
\hline 4 & 1 & 1 & -1 & -1 & 1625 & 237.5 & 6 & 22.5 & 142.41 \\
\hline 5 & -1 & -1 & 1 & -1 & 875 & 112.5 & 10 & 22.5 & 169.79 \\
\hline 6 & 1 & -1 & 1 & -1 & 1625 & 112.5 & 10 & 22.5 & 138.91 \\
\hline 7 & -1 & 1 & 1 & -1 & 875 & 237.5 & 10 & 22.5 & 275.72 \\
\hline 8 & 1 & 1 & 1 & -1 & 1625 & 237.5 & 10 & 22.5 & 183.12 \\
\hline 9 & -1 & -1 & -1 & 1 & 875 & 112.5 & 6 & 67.5 & 114.62 \\
\hline 10 & 1 & -1 & -1 & 1 & 1625 & 112.5 & 6 & 67.5 & 112.26 \\
\hline 11 & -1 & 1 & -1 & 1 & 875 & 237.5 & 6 & 67.5 & 186.58 \\
\hline 12 & 1 & 1 & -1 & 1 & 1625 & 237.5 & 6 & 67.5 & 141.95 \\
\hline 13 & -1 & -1 & 1 & 1 & 875 & 112.5 & 10 & 67.5 & 169.25 \\
\hline 14 & 1 & -1 & 1 & 1 & 1625 & 112.5 & 10 & 67.5 & 117.95 \\
\hline 15 & -1 & 1 & 1 & 1 & 875 & 237.5 & 10 & 67.5 & 272.29 \\
\hline 16 & 1 & 1 & 1 & 1 & 1625 & 237.5 & 10 & 67.5 & 175.12 \\
\hline 17 & -2 & 0 & 0 & 0 & 500 & 175 & 8 & 45 & 203.62 \\
\hline 18 & 2 & 0 & 0 & 0 & 2000 & 175 & 8 & 45 & 96.12 \\
\hline 19 & 0 & -2 & 0 & 0 & 1250 & 50 & 8 & 45 & 85.26 \\
\hline 20 & 0 & 2 & 0 & 0 & 1250 & 300 & 8 & 45 & 230.51 \\
\hline 21 & 0 & 0 & -2 & 0 & 1250 & 175 & 4 & 45 & 92.79 \\
\hline 22 & 0 & 0 & 2 & 0 & 1250 & 175 & 12 & 45 & 207.16 \\
\hline 23 & 0 & 0 & 0 & -2 & 1250 & 175 & 8 & 0 & 148.95 \\
\hline 24 & 0 & 0 & 0 & 2 & 1250 & 175 & 8 & 90 & 163.78 \\
\hline 25 & 0 & 0 & 0 & 0 & 1250 & 175 & 8 & 45 & 272.63 \\
\hline 26 & 0 & 0 & 0 & 0 & 1250 & 175 & 8 & 45 & 266.56 \\
\hline 27 & 0 & 0 & 0 & 0 & 1250 & 175 & 8 & 45 & 256.51 \\
\hline 28 & 0 & 0 & 0 & 0 & 1250 & 175 & 8 & 45 & 280.61 \\
\hline 29 & 0 & 0 & 0 & 0 & 1250 & 175 & 8 & 45 & 269.82 \\
\hline 30 & 0 & 0 & 0 & 0 & 1250 & 175 & 8 & 45 & 235.86 \\
\hline
\end{tabular}


The coded value of any intermediate levels can be calculated by using the following expression $[18,19]$.

$$
\mathrm{X}_{\mathrm{i}}=\frac{\left[2 \mathrm{X}-\left(\mathrm{X}_{\text {max }}+\mathrm{X}_{\text {min }}\right)\right]}{\left[\frac{\mathrm{X}_{\text {max }}-\mathrm{X}_{\text {min }}}{2}\right]}
$$

where, $X_{\max }$ is the upper level of the parameter, $X_{\min }$ is the lower level of the parameter and $X_{\mathrm{i}}$ is the required coded values of the parameter of any value of $X$ from $X_{\min }$ to $X_{\max }$.

The experiments are conducted as per the formulated design, and the images of the hole recorded at different conditions were presented in Table 5.

\subsection{Modeling of Drilling Parameters using RSM}

The second order response surface equations for the Thrust force $(\mathrm{Fz})$ in drilling of GFRP composites can be expressed as:

$$
F z=f(v, f, d, \theta)
$$

The general quadratic response-surface model, used to evaluate the parametric effects is as follows:

$$
Y=b_{0}+\Sigma b i x i+\Sigma b i i x i^{2}+\Sigma b i j x i x j
$$

where $\mathrm{b}_{0}$ is the coefficient for constant term and $b i, b i i, b i j$ are the coefficients for linear, square and interaction terms respectively.

The model chosen was a second degree response surface expressed as follows:

$F_{\mathrm{d}}=\beta_{0}+\beta_{1}(v)+\beta_{2}(f)+\beta_{3}(d)+\beta_{4}(\theta)+\beta_{5}\left(v^{2}\right)+\beta_{6}\left(f^{2}\right)+$

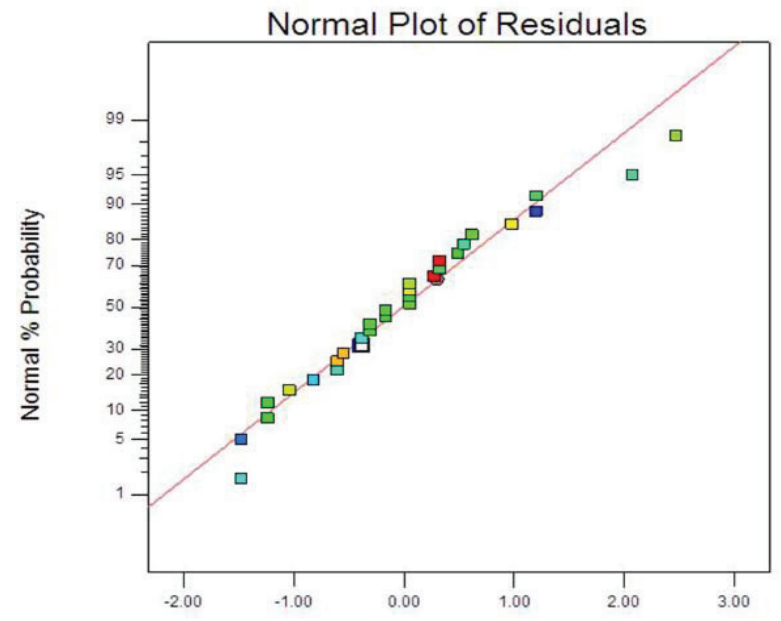

Figure 4. Normal probability plot. $\beta_{7}\left(d^{2}\right)+\beta_{8}\left(\theta^{2}\right)+\beta_{9}(v f)+\beta_{10}(v d)+\beta_{11}(v \theta)+\beta_{12}(f d)+\beta_{13}$ $(f \theta)+\beta_{14}(d \theta)$.

The model developed based on the above is given below:

Thrust force $=263.66500-24.35292^{*} v+33.30125^{*} f+$ $26.46792 * d+0.49542 * \theta-10.37938 * v^{2}-10.90188^{*} f^{2}-1.34063^{*}$ $d^{2}+7.03562 * \theta^{2}+0.97437^{*} v^{*} f-3.00563 \mathrm{~V}^{*} d-26.98177 \mathrm{~V}^{*} \theta-$ $24.94052 f^{*} d-26.95552 f^{*} \theta-25.35802 d^{*} \theta$

Analysis of variance (ANOVA) technique is used to check the adequacy of the developed empirical model and is presented in Table 6. The response of thrust force, the model F value of 9.86 implies that the model is significant.Values of "Prob>F" less than 0.0500 indicate that the model terms are significant. The calculated value of the $\mathrm{F}$ ratio of the developed model is less than the standard $\mathrm{F}$ ratio (from $\mathrm{F}$ table) value at a desired level of confidence (say 95\%), then the model is said to be adequate within the confidence limit.

The "Predicted R-Squared" of 0.98 is in reasonable agreement with the "Adjusted R-Squared" value. The calculated value of the $\mathrm{R}$ ratio of the developed relationships exceeds the standard tabulated value of the $\mathrm{R}$ ratio for a desired level of confidence (say 95\%), then the relationship may be considered to be adequate within the confidence limit and hence the model may be accepted. The experimental data and the predicted data by the using aforesaid model are analysed by using residual analysis. In this method, confidence interval and prediction interval could be close to each other and narrower intervals provide a higher degree of precision which is presented in Figure 4 and the predicted value versus the actual experimental value is presented in Figure 5 which shows better correlation.

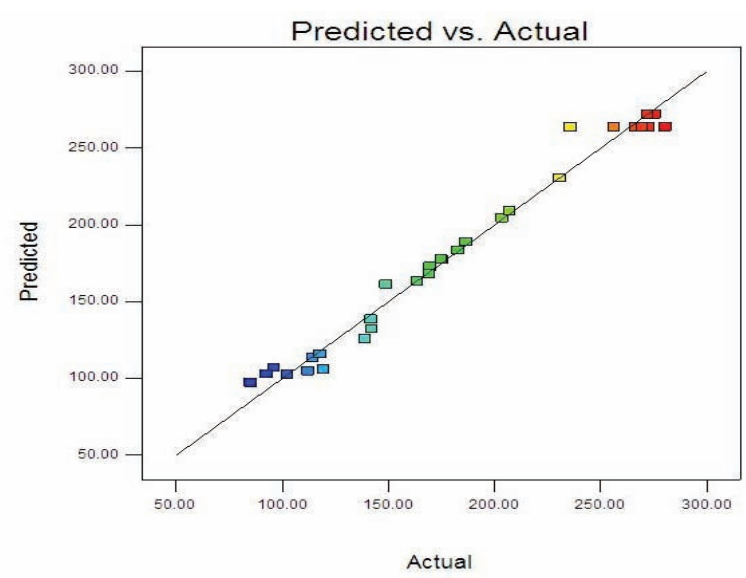

Figure 5. Comparison plot for thrust force using Multifaceted drill bit. 
Table 5. Record of hole quality using Multifaceted Drill

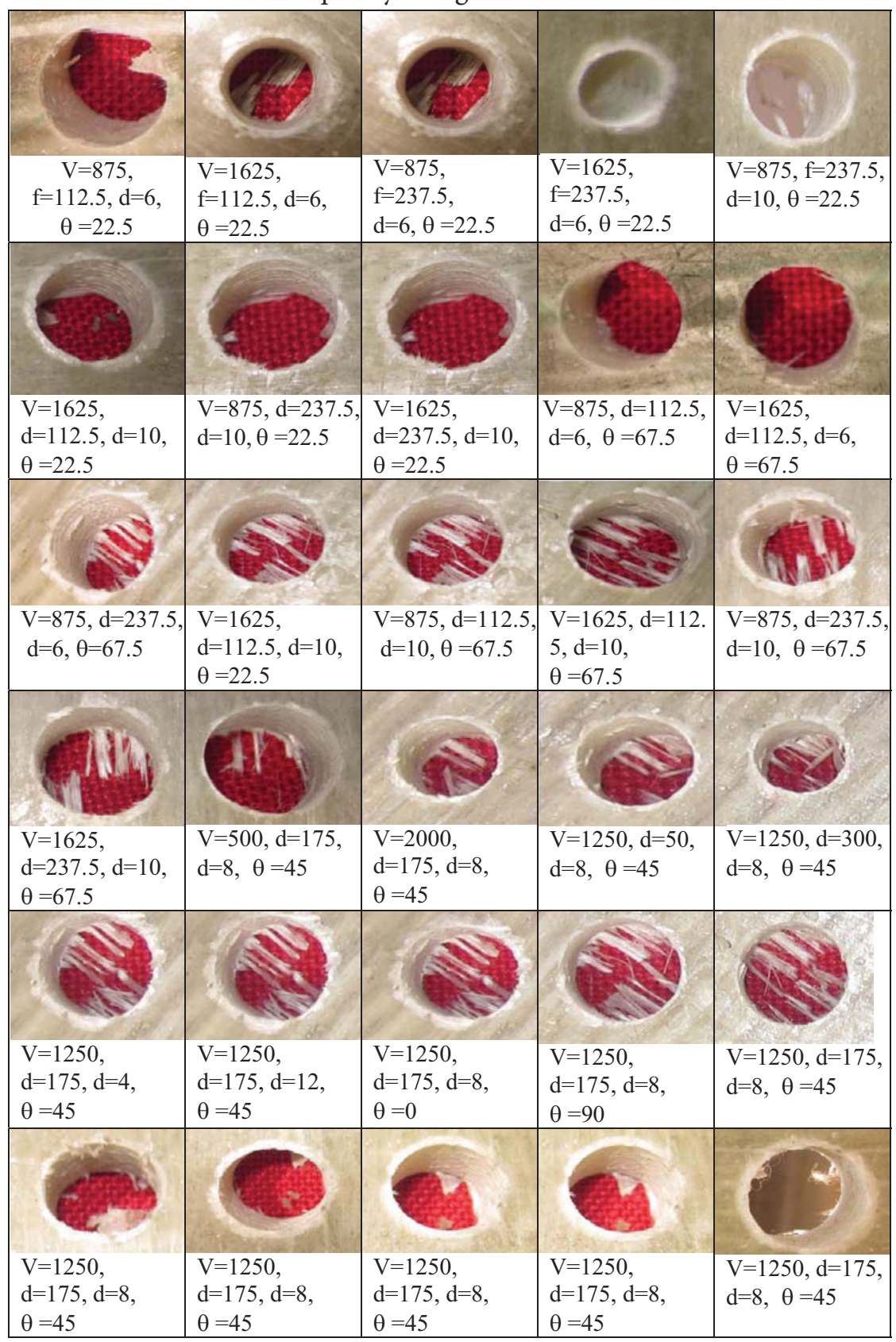

Table 6. Analysis of variance for response surface regression model

\begin{tabular}{lrrrrrc}
\hline Source & DF & Seq SS & Adj SS & Adj MS & \multicolumn{1}{c}{ F } & P \\
\hline Regression & 14 & 114505 & 114505 & 8178.9 & 52.45 & 0.000 \\
Linear & 4 & 57628 & 57628 & 14407.0 & 92.39 & 0.000 \\
Square & 4 & 52271 & 52271 & 13067.8 & 83.81 & 0.000 \\
Interaction & 6 & 4606 & 4606 & 767.6 & 4.92 & 0.006 \\
Residual Error & 15 & 2339 & 2339 & 155.9 & & \\
Total & 29 & 116844 & & & & \\
R-Sq $=98.00 \%$ & & & & & & \\
\hline
\end{tabular}




\section{Results and Discussions}

GFRP composites finds increased application of in many engineering fields ranging from automotive to aeronautical industries. Drilling is an un avoidable process in manufacturing, since parts cannot be made near net-shape. During drilling of GFRP composites, many problems encountered including defuzzing, spalling, delamination, fiber-pull out etc. Among these problems, delamination due to thrust force causes severe damage to the product, which leads to the rejection of material. The industrial engineers spending effort to minimize the thrust force which in turn produce delamination. The experts may easily analyse the damages occurred in drilling of GFRP composites by the picture taken from Scanning electron microscope. The surface profiles obtained and the enlarged view of the profile observed in drilling of GFRP composites are presented in Figure 6a and $6 \mathrm{~b}$ respectively.

In Figure 6a, there is a smooth surface observed in some region of the specimen, whereas some region does not show clear effect on the work surface. This may be due to the interrupted cutting takes place due to the multiedge drill tool used for this purpose. Figure $6 \mathrm{~b}$ shows the SEM microstructure of the specimen observed. The result indicated that there is a insufficient distribution of resin and fibre in the cut surface. During the cutting process, there is a small variation in surfaces observed, which is indicated in the figure.

\subsection{Effect of Drilling Parameters on Thrust Force}

GFRP drilling is complicated comparing to machining of metals and alloy due to its anisotropic nature. Proper care

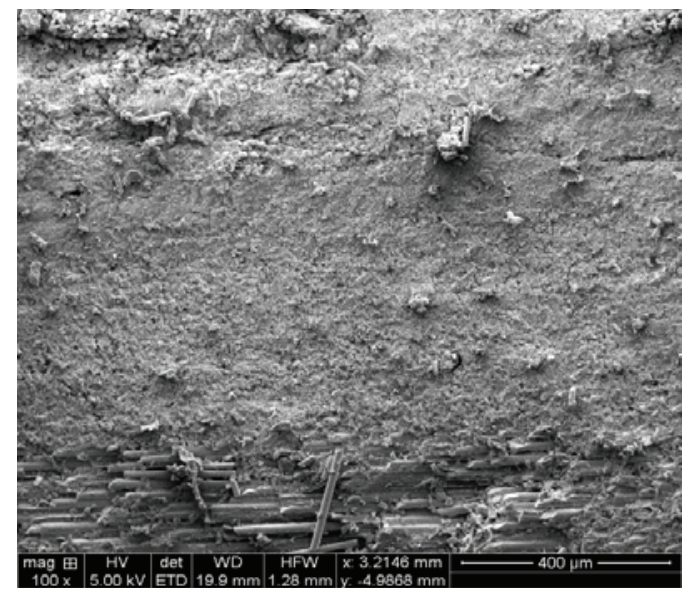

Figure 6a. Typical surface profile observed. should be taken to select the range of parameters. The effect of different parameters such as spindle speed, feed rate, drill diameter and fiber orientation angle in drilling GFRP composites have been discussed in detail in the following paragraph.

Figure 7(a-f) shows the interaction effect of the parameter on the drilling of GFRP composites. The effect between the parameter spindle speed and feed rate is presented in Figure $7 \mathrm{a}$. The figure indicated that the increase of feed rate increases the thrust force in drilling of GFRP composites. The reason being the increase of feed rate increases the load on the tool, which resulted in increase of thrust force.

Figure $7 \mathrm{~b}$ shows the effect of spindle speed and drill diameter versus the thrust force in drilling of GFRP composites. The result indicate that the increase of drill diameter increase the contact area between the drill and workpiece which resulted in high thrust force, whereas the increase of spindle speed does not show any clear trend as observed before. Figure $7 \mathrm{c}$ shows the effect of feed rate and drill diameter on thrust force in drilling of GFRP composites. The increase of drill diameter and feed rate increases the thrust force in drilling of GFRP polyester composites as discussed earlier.

The effect of spindle speed and fiber orientation angle on thrust force in drilling of GFRP composites is shown in Figure $7 \mathrm{~d}$. The increase in the fiber orientation angle increase the thrust force upto $45^{\circ}$, after that the increase is not affected so much. The high thrust force is observed only at $45^{\circ}$. The spindle speed shows the same trend as discussed earlier. The effect of feed

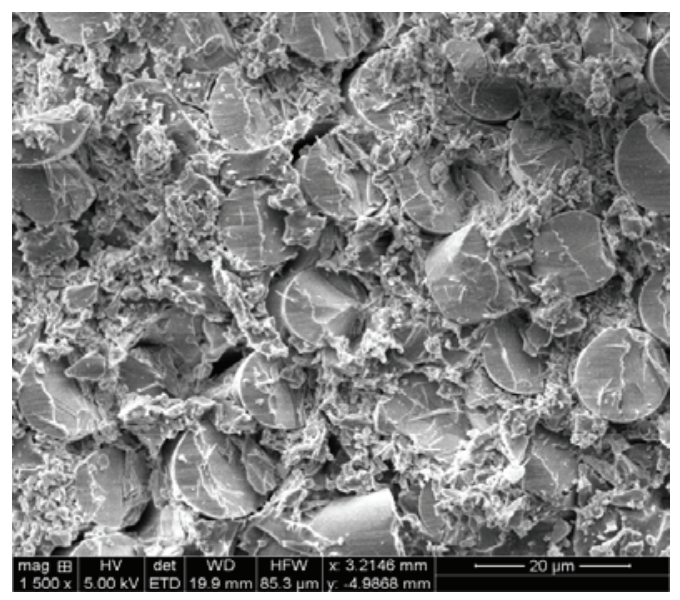

Figure 6b. Enlarged view of the profile observed. 


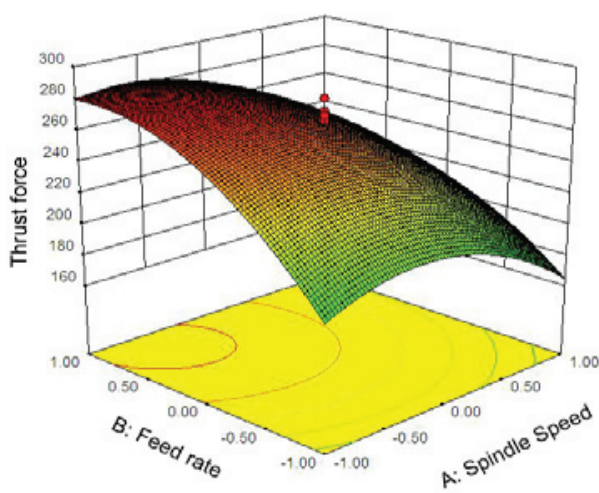

(a) Spindle speed Vs Feed rate

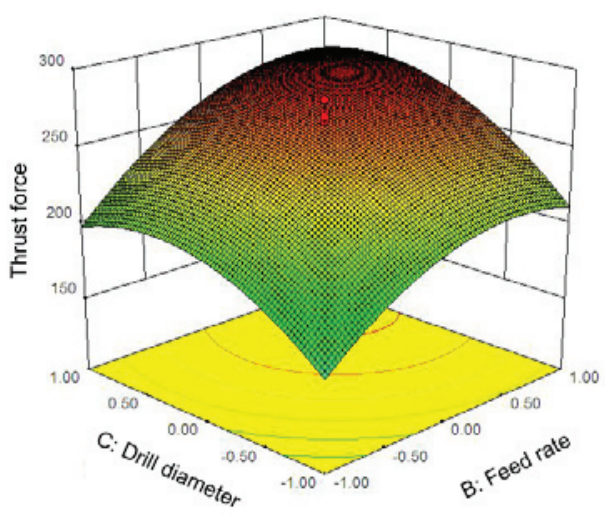

(c) Feed rate Vs Drill diameter

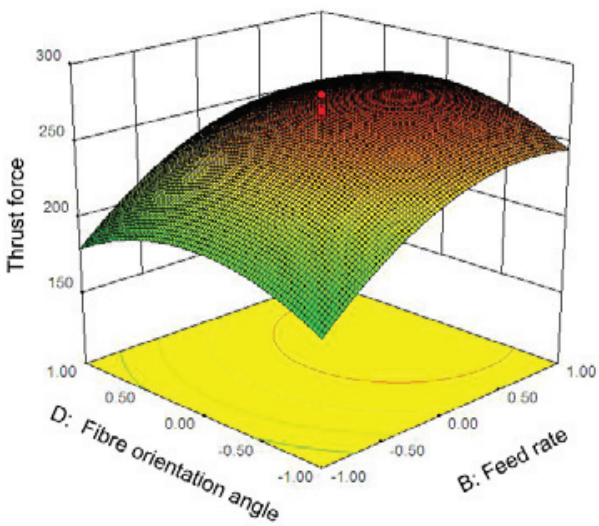

(e)Feed rate Vs Fiber orientation angle

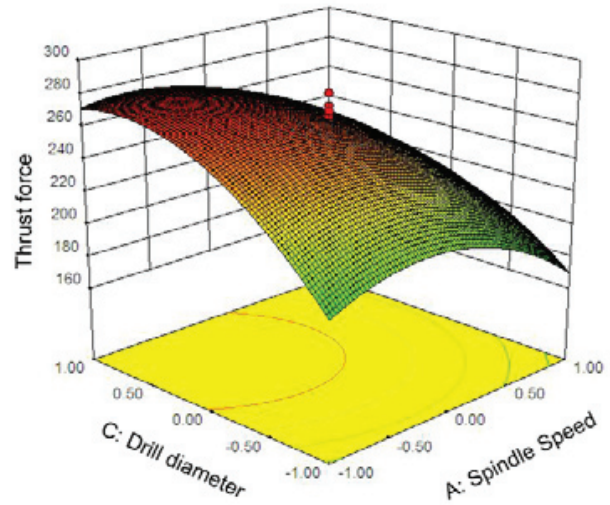

(b) Spindle speed Vs Drill diameter

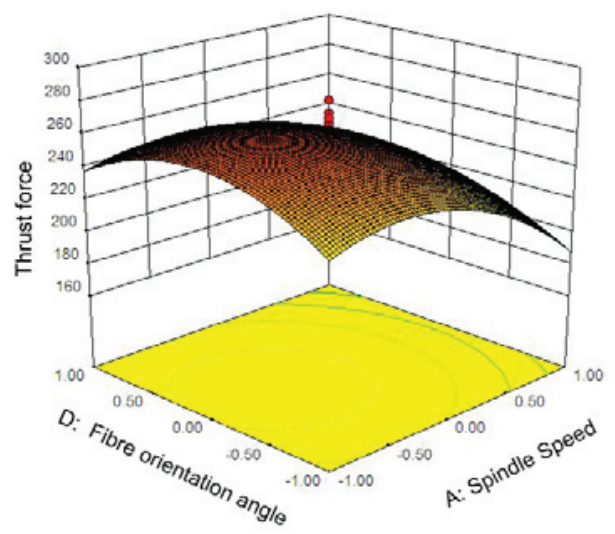

(d)Spindle speed Vs Fiber orientation angle

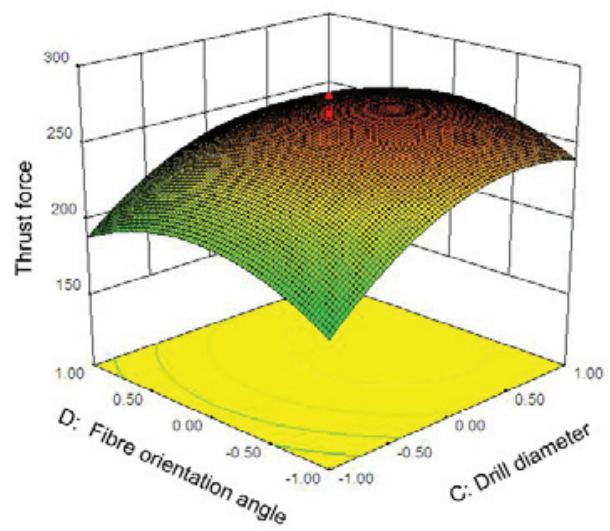

(f)Drill diameter Vs Fiber orientation angle

Figure 7. (a,b,c,d,e and f) 3-D response graphs for Thrust force in drilling GFRP composites by using Multifaceted drill.

rate and fiber orientation angle with thrust force and the effect of drill diameter and fiber orientation angle with thrust force is presented in Figure $7 \mathrm{e}$ and $7 \mathrm{f}$. The figure shows that the increase of feed rate and drill diameter increases the thrust force in drilling of GFRP composites, whereas $45^{\circ}$ fiber orientation angle shows the maximum thrust force.

From the above figures it has been clearly seen that minimum feed rate, reasonably small drill diameter and $0^{\circ}$ or $90^{\circ}$ fiber orientation angle is preferred for 
minimizing the thrust force in drilling of GFR-Polyester composites.

\section{Conclusions}

- The experiments are conducted as per Central composite design matrix using Multifaceted drill bit.

- The developed mathematical model can be effectively used to minimize thrust force in drilling GFRP composites.

- The results indicated that the effect of fiber orientation angle plays a major role in drilling GFRP composites.

- $0^{\circ}$ or $90^{\circ}$ fiber orientation angle is recommended for minimizing thrust force in drilling of GFRP composites.

\section{References}

1. Davim J P, Reis P et al. (2004). A study on milling of Glass fiber reinforced plastics manufactured by hand lay-up using statistical analysis (ANOVA), Composite Structures, vol 63(3-4), 493-500.

2. Murphy C, Byrne G et al. (2002). The performance of coated tungsten carbide drills when machining carbon fibre-reinforced epoxy composite materials, Proceedings of the Institution of Mechanical Engineers (Part B: Journal of Engineering Manufacture), vol 216(2), 143-152.

3. Engin S, Altintas Y et al. (2000). Mechanics of routing medium density fiberboard, Forest Production Journal, vol 50(9), 65-69.

4. Abrao A M, Faria P E et al. (2007). Drilling of fiber reinforced plastics, Journal of Materials Processing Technology, vol 186(1-3), 1-7.

5. Latha B, and Senthilkumar V S (2009). Application of artificial intelligence for the prediction of delamination in drilling GFRP composites for obtaining precision holes, International Journal of Precision Technology, vol 1, No. 3/4, 314-330.

6. Khashaba, U A (2004). Delamination in drilling GFRP thermoset composites, Composite Structures, vol 63(3-4), 313-327.

7. Claudin C, Poulachon G et al. (2008). Correlation between drill geometry and mechanical forces in MQL conditions, Machining Science and Technology, vol 12(1), 133-144.

8. Montgomery D C (2006). Design and Analysis of Experiments, Wiley India (P) Ltd., New Delhi, India.

9. Stone S, and Krishnamurthy K A (1996). Neural network thrust force controller to minimize delamination during drilling of graphite -epoxy laminates, International Journal of Machine Tools and Manufacture, vol 36(9), 985-1003.

10. Dabnun M A, Hashmi M S J et al. (2005). Surface roughness prediction model by design of experiments for turning machinable glass ceramic (Macor), Journal of Materials Processing Technology, vol 164(165), 1289-1293.

11. Gaitonde V N, Karnik S R et al. (2010). Machinability evaluation in unreinforced and reinforced peek composites using response surface models, Journal of Thermoplastic Composite Materials, vol 23(1), 5-18.

12. Ramesh S, Karunamoorthy L et al. (2008). Surface roughness analysis in machining of titanium alloy, International Journal of Materials and Manufacturing Processes, vol 23(2), 174-181.

13. Latha B, and Senthilkumar V S (2009). Analysis of thrust force in drilling glass fiber-reinforced plastic composites using fuzzy logic, Materials and Manufacturing Processes, vol 24(4), 509-516.

14. Palanikumar K, Karunamoorthy L et al. (2006). Modeling and analysis of cutting force in turning of GFRP composites by CBN tools, Materials and Design, vol 27(7), 862-871.

15. Palanikumar K, and Karthikeyan R (2007). Assessment of factorsinfluencingsurfaceroughnessonthemachiningof Al/SiC particulate composites, Materials and Design, vol28(5), 15841591.

16. Rajamurugan $\mathrm{T}$ V, and Shanmugam K (2011). Optimization of machining parameters for drilling GFR Poly-ester composites, Journal of Emerging Science and Technology, vol 2, 31-39.

17. Rajamurugan T V, Shanmugam K et al. (2012). Analysis of delamination in drilling glass fiber reinforced polyester composites, Materials and Design, vol 45, 80-87.

18. Palanikumar K (2007). Modeling and analysis for surface roughness in machining glass fibre reinforced plastics using response surface methodology, Materials \& Design, vol 28(10), 2611-2618.

19. Box G E P, Hunder W H et al. (1978). Statistics for experiments, New York, John Wiley and Sons. 